\title{
LEARNER PERCEPTIONS IN DESIGN CRITIQUES: IMPACT ON CREATIVE DEVELOPMENT
}

\author{
E. F. Eshun ${ }^{1}$ and J. Adu-Agyem ${ }^{2}$ \\ ${ }^{I}$ Department of Communication Design \\ ${ }^{2}$ Department of General Art Studies \\ Faculty of Art, Kwame Nkrumah University of Science and Technology, Kumasi, Ghana
}

\begin{abstract}
This paper is an exploratory study on the use of criticism as pedagogical tool in Communication Design studio to support creative development. The quantitative research method was used to explore the role of the teacher in design critiques and how learners perceive criticism, critiques and teacher interaction on their skill and knowledge acquisition. The study was conducted bearing in mind the social factors in the design studio. The study is also limited to the perceptions of Communication Design students at the Kwame Nkrumah University of Science and Technology. The subjects for the study comprised undergraduate students of the Department of Communication Design. A structured questionnaire was administered using purposive sampling method to select 140 students. The results revealed that studio critique was a valued activity and that participation in critique was shaped by some social factors such as rapport and perceptions of shared critiques among participants especially in large-numbered classes.
\end{abstract}

Keywords: design critiques, criticism, creative development

\section{INTRODUCTION}

Although very little literature exist on the theories of socio-cultural effects on graphic design critique, the paper attempts through the study, to examine some possible impacts of social factors in class interaction. Studio critique is a prime component of art and design education. Critique was borne out of criticism. Criticism is a Greek verb, krinein, which means to make distinction or to separate (Attoe, 1978). Critique provides the ideal environment to talk about art and design and receive feedbacks that are essential in the design process (Graham, 2003; Shaffer, 1999). Studio critique is re- spected for its input in student achievement and knowledge construction especially with creative project outcomes (Taylor, 2008). Its introduction into design education dates back to the late $17^{\text {th }}$ century, with the Beaux-Arts theory of education which served as basis for the development of modern design education. It was based on private tutorial between a master of design and a student (Graham, 2003). Under this academic structure, were five educational practices: the division of students into ateliers or studios, the tradition of old students assisting the younger pupils, the teaching of design by practitioners, judgement of designs by a trained 
jury of practitioners and the system of 'esquisse' or the sketching of design solutions (Malecha, 1985).

The main pedagogical method used in those design critiques is criticism. The studio activities included teacher demonstration, desk criticism (desk crits) interpersonal discourse between teacher and student and juries for final solutions. Criticism which is applied in studio critiques is judgemental (Goldblatt, 2006). Criticism has both written and verbal forms which are extensively used in schools. The literary and art criticism are used to inform and promote the art (Goldblatt, 2006), thus very essential curriculum component, though its application is sometimes undermined by both the students and instructors (Malo, 2001).

The existence of social interaction and network between participants in design critiques is undoubtedly crucial and the acceptance of criticism as creative behaviour that has to be acquired for critique participation and creative development becomes vital in conducting effective studio critiques. The challenges of thorough instructor preparation and student acceptance of criticism continue to pose a threat to the design critiques (Graham, 2003).

In this paper we report on our investigations into learners' perception of studio critique in Communication Design and its impact on their art production and creative skill acquisition. Central to this study is also the role-play of the teacher in creating the appropriate learning environment.

\section{METHODS AND PROCEDURES}

For the purpose of the study, convenience sampling was considered appropriate to cover the students available at the time of distribution of the questionnaire. The sample population was polled from the students of the Department of Communication Design at the Kwame Nkrumah University Science and Technology, in Kumasi, Ghana, which offers a 4-year degree programme in Communication Design. A sam- ple of 140 students was drawn from all the years. The sampled population comprised nine (9) first year students, 59 second year students, 17 third year and 55 final year students. All the respondents for the study were mainly of Ghanaian descent.

\section{Instrument}

A quantitative approach was used in this exploratory study to investigate learners' perceptions on design studio critiques and their impact on students' creative development. Data on learner perceptions were collected with a structured questionnaire, consisting of 40 items designed to assess the students' attitude toward studio critique. The questionnaire concerned topics such as aesthetic, appreciation and criticism, effectiveness, the instructor's role in critiques, student reaction to critique and student achievement. Points were scored by giving one point each time the student chose the most satisfied response to the multiple choice items. The items used to collect data in the student questionnaire were based on preliminary studies conducted among the students during the earlier phase of the research. The research instrument was made to contain unbiased questions that could affect the results. The Statistical Package for the Social Sciences (SPSS) Version 15 was used for the statistical analysis. Descriptive statistics, including mean and standard deviation were used to summarize the data. Frequencies, percentages and cumulative percentages were recorded for demographic data.

\section{RESULTS AND DISCUSSION}

A total of 150 questionnaires were distributed to the students, out of which 140 copies were returned, representing $93 \%$ response rate. This is significant and compares with the success rate considered by Oppenheim (1992), which suggests self-administered questionnaire distributed and completed within the classroom assures high return. In many of the survey responses, students shared similar views on several aspects of studio critique, including understanding of criticism, feedback, teacher support 
and impact on creative development. The results revealed that critique was a valued activity and that participation in critiques was shaped by social factors such as rapport, trust and value judgment. Figure 1 provides a graphic representation of population distribution in the four year groups. Nine of the participants were first year students constituting 6\%,59 were second years representing 43\%, 17 were third years representing $12 \%$ and 55 were fourth year students representing $39 \%$. The participation was voluntary and anonymous.

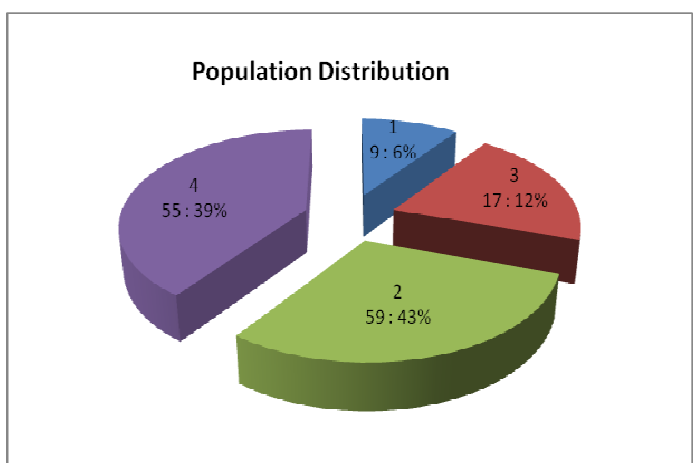

Figure 1: Population Distribution

\section{Art Aesthetics and Criticism}

Student's appreciation and understanding of aesthetics and criticism is crucial to their creative development (Lowenfeld and Brittain, 1987). Figure 2 shows the summary of the study variables under appreciation of aesthetics and criticism. The results show strong students' understanding and appreciation of aesthetics and criticism. In responding to knowledge in aesthetics and criticism, 124 of the respondents representing $88.6 \%$ admitted their understanding of aesthetics. It is proved further in the follow up items, where $133(95 \%)$ and 127 $(90.7 \%)$ were scored respectively for discovery meaning and visual inventory within art, which are the key components in evaluation of artworks: description, interpretation and evaluation which are in line with the report by Bates (2000) indicating that "these procedures are to encourage students to look at a work long enough to really see, to keep students from making immediate judgments without having paid enough attention to a work's visual qualities" Daracott (1990), Gilbert (1992) and Graham (2003) shared similar views.

The results obtained for material usage, skill of artist and the use of creative process, $65.7 \%$, $87.0 \%$ and $90.0 \%$ respectively are significant and pointers to divergent thinking skills and application of reflective learning (Cuff, 2000). Another result (Figure 2) worth noting is that $40 \%$ was scored for immediate judgment which was expected, and by this result it is indicative that respondents were developing 'suspended judgment' attitudes that are critical in the early stages of creative process. This result is consistent with what Bates (2000) recommended "to keep students from making immediate judgments".

\section{Lecturers' Verbal Feedback}

Figure 3 shows the results obtained for students' appreciation of lecturers' verbal feedback content. They (i.e. students) gave a high score for lecturers' critique of students' artworks $(95.7 \%)$; fairness $(70.7 \%)$; lecturers' commendation of students' art production $(87.9 \%)$ and lecturers' constructive comments $(77.2 \%)$. These are indicative of the supportive role played by lecturers in the students' art production and during critiques as noted by Taylor and McCormack (2006) that "Oral feedback plays an important scaffolding role in developing socially held and shared knowledge of creativity and the design of artifact". A low score of $39.3 \%$ of the respondents on enough time for critiques is indicative of students' dissatisfaction of time for studio critiques, since it results in some students losing lecturers' feedback, a problem reported by Butcher and Cash (2007) as "the most difficult aspects of visual assessment/verbal feedback as a parity of interaction across the group". This is inevitably more difficult in large groups. Even when time limits were stated at the outset of the session there was no evidence that the allocated times were being met. 


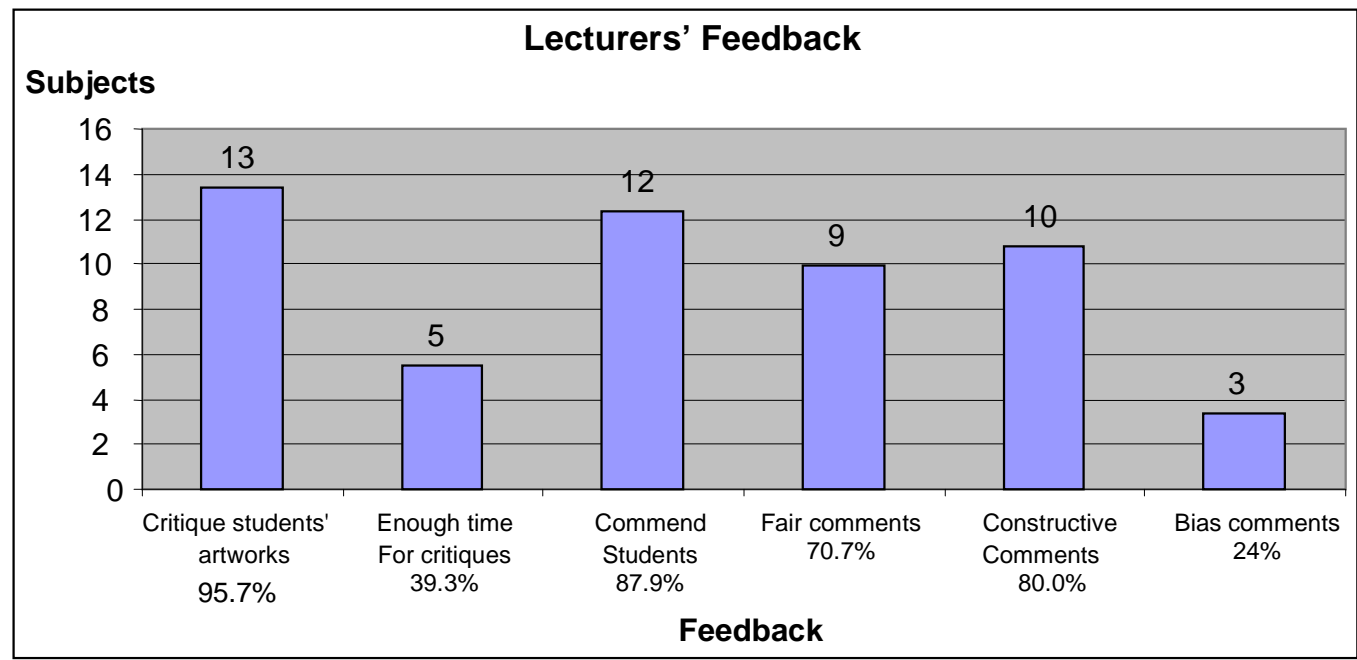

Figure 3: Lecturer's feedback in studio critique

\section{Lecturers' Actions in Critiques}

Respondents description of their lecturers' actions in critiques", were scored and ranked in Table 1. Lecturers talk about all artworks topped the table with $35.7 \%$ showing that students appreciate lecturers' verbal critiques which may contribute to setting the right tone and providing a fair atmosphere for students to also contribute to the discussion. In this leadership style according to Cameron (2003) "traditional power relationships are broken down". Students have the opportunity to discuss the works with jurors and with each other all within an environment of mutual respect. The items "lecturers select strong works and talk about their success" (i.e. 48 or $34.3 \%$ ) and "lecturers select weak works and talk about their failures" (17 or $12.1 \%$ ) show that lecturers adopt purposive sampling method for critiques similar to those observed by Boling (2005) which indicated that "the instructor chose which work would be discussed". Only $7.1 \%$ said lecturers were selective in their discussions. This situation shows students could be sensitive about lecturers' comments. Similar observations were also made by Stead (2003) who stated that "critique could surprise either pleasantly or unpleasantly.... To some extent this scenario comes about because students sometimes perceive either rightly or wrongly that their teachers and guest jurors are biased".

Table 1: Lecturers' actions in critiques

\begin{tabular}{lll}
\hline & Frequency & Percent \\
\hline Lecturers select strong works and talk about their successes & 48 & 34.3 \\
Lecturers select weak works and talk about their failures & 13 & 9.3 \\
Lecturers selective in their discussions & 10 & 7.1 \\
Lecturers seldom talk about student works & 17 & 12.1 \\
Lecturers talk about all artworks & 50 & 35.7 \\
Missing & 140 & 100 \\
\hline
\end{tabular}


Learner Perceptions in Design Critiques...

\section{Peer Support}

Gradually peer support is gaining unprecedented attention in education research in recent times. The study sought to find out some possible reasons respondents have for their comments when participating in studio critiques. Results from Table 2 show respondents ranked the item "to give hope to the designer" highest with $32.9 \%$. It is suggested that one of their several reasons could probably offer support to peers and self. This agrees with similar findings reported by Justice et al, (2003) that "the majority of students highly regarded and sought for fellow students' advice". The second topmost score was that "artwork should be appreciated" with a score of $22.9 \%$ showing that respondents appreciate the role of critique in creative development and recognition of criticism in art appreciation. Another comment which is of interest is "object condemnation" with a score of $5.0 \%$. This result shows that students were a bit tolerant when their artworks were commented on and possibly accepted "hard criticisms" during critiques. This is also suggestive that students were 'warming' themselves to participate in professional design practice.

\section{Peer Review (Feedback)}

Table 3 provides an outlook on sampled population's response to questions on peer review. Results from Table 3 show modest scores for peer input in critiques; peers' constructive comments scored $51.4 \%$, peers show fairness $54.3 \%$ and peers' participation, $65.7 \%$. Even though the general outlook of the results was moderate, one may like to consider the effect of socio-metric dynamics in the classroom situation. Agyeman (1993) indicated that students develop subcultures within the classroom environment. Where group member's interest is defended and protected by other members in the classroom. This behaviour can assume heightened proportions in societies where cultural values have greater influence on how people relate to one another for example in Ghanaian societies. Also in a reclusive class, where academic activities are structured on teacherled discussions, it was observed that students tend to downplay the importance of peersupport but rather tend to prefer teacher-centred learning. This outcome was also evident in earlier results presented in Figure 2 and Table 1, where 'constructive comments from teachers and peers were scored $80 \%$ and $51.4 \%$ respectively. These results show students preference for teacher comments, which corroborate with Cameron (2003) assertion that "It is more likely that students will listen to tutors' comments if they know that they will benefit from them".

Nevertheless, the results give some indications of the positive impact of peer-support in studio critique and this was also reported by Cameron (2003). Although $26.4 \%$ of the population showed their passiveness during critiques, students' inaction may also be that students would have commented and suggested options to peers before the critique and students may be suffering from "critique fatigue" (Justice et al,

Table 2: Why Students comments

\begin{tabular}{lll}
\hline & Frequency & Percent \\
\hline Artwork should be appreciated & 32 & 22.9 \\
Give hope to the designer & 46 & 32.9 \\
Object condemnation & 7 & 5.0 \\
Artist worked by preference & 9 & 6.4 \\
Other reasons & 17 & 12.1 \\
No comment & 28 & 20.0 \\
TOTAL & 140 & 100 \\
\hline
\end{tabular}


Table 3: Peer Feedback

\begin{tabular}{lllllll}
\hline & \multicolumn{2}{c}{ Positive } & \multicolumn{3}{c}{ Neutral } & \multicolumn{2}{c}{ Adequate } \\
\hline & Freq. & $\%$ & Freq. & $\%$ & Freq. & $\%$ \\
Peer comments constructive & 72 & 51.4 & 9 & 6.5 & 59 & 42.1 \\
Peers show fairness & 76 & 54.3 & 27 & 19.2 & 37 & 26.4 \\
Peers participate in critique & 92 & 65.7 & 11 & 7.8 & 37 & 26.4 \\
Peers bias & 68 & 48.5 & 13 & 9.3 & 59 & 42.1 \\
Self participation in critique & 89 & 63.6 & 9 & 6.4 & 42 & 30.0 \\
\hline
\end{tabular}

2003).

\section{Studio Critiques}

Table 3 shows the variation in the impact of studio critiques on the creative development of the students. A significant proportion of the respondents (93.9\%) believed that critique is an essential component of their communication design education. Another significant proportion of $78.6 \%$ of the respondents also believed that critiques had an impact on their creative performance, when they responded to the item, 'If student's works improved after critiques'. This was again reinforced in the follow-up question "whether the impact was positive or negative", a high score of $94.1 \%$ was recorded for the item. It has been evident in subsequent studio presentations on work-in-progress that students' artworks showed remarkable improvement and students' confidence in talking about their work in studio improved tremendously. Nearly all respondents $(94.0 \%)$ agreed that the value for improved art production is undeniably very important, because it is compatible with knowledge construction and acquisition (Taylor, 2008).

In general, students benefited from their anxiety (see Table 4). As huge as $47 \%$ to $59.3 \%$ were nervous before and during the studio critiques, but they came out of the critiquing more confident and competent with a score of $93.6 \%$. A total percentage of $97.2 \%$ appreciated the role of critiques in their design education and 95.0\% would like to see more regular and effective critiques as reiterated by Dickson (2008) that "developing more regular, fluid and structured interactions between students and teachers as well as between students perhaps encourages a greater openness in the group and thereby strengthens both studio culture and critical conversation".

\section{IMPLICATIONS}

The findings reported in the study have implications for teaching and learning of communication design - tools for effective critiques and how teachers use them. One major implication is that students should be encouraged to build and negotiate shared norms to guide their studio practice of critique. The instructor/teacher who plays an important role as a facilitator in the studio critique should be cognizant of the need to help build congenial and dynamic teaching and learning environment to establish trust, cohesion and rapport among participants in critiques. Undoubtedly, studio critique would continue to play an essential fulcrum in knowledge and skill acquisition in problem-based classroom environment. Key to its success and effectiveness is how the teacher/facilitator brings his/her creative leadership role to bear by stimulating and encouraging dialogue, reflective thinking, control and enthusiasm among anxious and expectant students. To exercise this duty, the teacher/facilitator should 
challenge the traditional status quo, where the educator wields so much power to intimidate and create tension-filled environments, which compel students to become passive participants. Also important is to engage participants prior to critique to develop assessment criteria for creative process and product - what to be assessed and how to communicate an opinion in a more friendly and supportive manner.

Another implication is the issue of large-class numbers and how it negatively influences students participation in critiques. It would require more innovative ways of organizing the critiques if it should be a regular activity to help in the creative process. Failure to establish a system that takes into consideration all short comings could only help slow and introvert students to stay clear off the spotlight, foster apathy and timidity among creative students.

\section{CONCLUSIONS}

The conclusions derived from the study are as follows: In general, more emphasis should be placed on the innovative assessment of the creative process rather than the end product in assessment. Efficient, effective and regular critiques will improve students' performance and achievements during their design education. Results showed that a better relationship between lecturers and students is ideal in improving students' performance, thus more interaction between the teacher-student during the creative process is very important. Moreover, large class numbers for studio-based learning is not the best considering time constraint and small classroom space. Lastly social interaction issues could have negative impact on student learning, if care is not taken to minimize their influence especially among students and between the teacher and the students.

Table 4: Studio Critiques

\begin{tabular}{lllllll}
\hline & Positive & \multicolumn{2}{l}{ Neutral } & \multicolumn{2}{c}{ Adequate } \\
\hline & Freq. & $\%$ & Freq. & $\%$ & Freq. & $\%$ \\
Does critique affect creative production? & 105 & 76.1 & 10 & 7.1 & 25 & 17.9 \\
If students are reflective on comments & 123 & 87.8 & - & - & 12 & 8.6 \\
Impact of critiques positive or negative & 132 & 94.1 & - & - & 8 & 5.8 \\
Do students enjoy critiques? & 102 & 72.9 & 5 & 3.6 & 30 & 21.4 \\
If students artworks improves after cri- & 110 & 78.6 & 8 & 5.7 & 22 & 15.7 \\
tiques & & & & & & \\
If student's works declines after critiques & 53 & 37.9 & 2 & 1.4 & 85 & 60.7 \\
Students nervous when going for critiques & 67 & 47.9 & 14 & 10.0 & 14 & 10.0 \\
Student confident when going for critiques & 88 & 62.8 & 9 & 6.4 & 43 & 30.7 \\
Students nervous when works are discussed & 83 & 59.3 & 12 & 8.6 & 45 & 32.1 \\
If students are more confident after critique & 110 & 78.6 & 9 & 6.5 & 21 & 15.0 \\
If critiques are necessary & 131 & 93.6 & 4 & 2.9 & 5 & 3.6 \\
Should critique be a regular feature & 129 & 92.1 & 7 & 5.0 & 4 & 2.9 \\
\hline
\end{tabular}




\section{REFERENCES}

Agyeman, D. K. (1993). Sociology of education for African students, Accra: Black Mask Ltd.

Attoe, W. (1978). Architecture and critical lmagination. New York: John Wiley \& Sons.

Bates, J. K. (2000). Becoming an art teacher. $1^{\text {st }}$ ed. California: Wadsworth Publishing.

Boling, E. (2005). Design culture in fine arts studio programs. Retrieved September 6, 2009 from http://www.indiana.edu/ idt/ shortpapers/documents de sign_culture_boling.html.

Butcher, J. and Cash, C. (2007). Talkback: the student experience of learning through verbal feedback in the studio. Retrieved August 12, 2009 from the World Wide Web; http://www.falmouth.ac.uk/452/ learning-and-teaching-22/learning-andteaching-research-centre-158/ltrc- publications-573.html

Cameron, M. (2003). The Jury's Out: A Critique of the Design Review in Architectural Education. Paper presented ACUADS Annual Conferences 2003. Retrieved August 23, 2009 from the World Wide Web; http:// www.acuads.com.au/conf2003/ p a p e r s _refereed/cameron.pdf

Cuff, D. (2000). "Studio Crit The studio is the heart of the architect's education, but it may be time for a checkup", Architecture Vol. 89; Part 9, pp 76-77.

Daracott, J. (1990). Art criticism: A user's guide, London: Bellew Publishing.

Dickson, M. (2008). Formative assessment in the formation of studio culture, National Forum on studio teaching assessment. Australian Learning \& Teaching Council.
New South Wales: University of New South Wales.

Gilbert, R. (1992). Living with art. $3^{\text {rd }}$ ed. New York: McGraw-Hill, Inc.

Goldblatt, P. (2006). How John Dewey's Theories Underpin Art and Art Education. Education and Culture 22.1 pp. 17-34.

Graham, E. M. (2003). Studio critiques: Student and faculty perception and reality, Retrieved July 11, 2009 from http:// www.etd.isu.edu/dos/available/etd0611103-184324.

Justice, L., Cutt, R., Fowler, L., LaRocher, N., Nelson, M. and VanHill, J. (2003). Defining and refining the industrial design critique in educational settings, Georgia Institute of Technology, Retrieved June 6, 2009 from http://www.idsa.org/W e b Modules/ Articles/articlefiles/ ed.../19.pdf

Lowenfeld, V. and Brittain, W. L. (1987). Creative and mental growth. $8^{\text {th }}$ ed. New Jersey: Prentice-Hall, Inc.

Malecha, M. J. (1985). The design studio, La Verne, CA: Architecture and Research Press.

Malo, P. (2001). How do you evaluate a design? Retrieved July 26, 2009 from the World Wide Web; http:// www.designcommunity.com/ d i s c u s sion/10907.html

Oppenheim, A. N. (1992). Questionnaire design, interviewing and attitude measure ment, London: St Martins Press.

Shaffer, D. W. (1999). The design studio as a model for education, Retrieved August 6, 2009 from the World Wide Web; http:// dws.www.media.mit.edu/people/dws// papers/designstudio/index.html 
Stead, N. (2003). Producing critical thinkers, designing critical objects: re-examining the role of critique in architectural education, Conference of the Association of Architecture Schools Austrasia, ed Sandra Kaji-O'Grady et. al., Melbourne, Australia, pp. 3-12.

Taylor, M. J. (2008) Spoken feedback using mobile technology national forum on stu- dio teaching assessment, New South Wales: University of New South Wales.

Taylor, M. J. and McCormack, C. (2006). Effective verbal feedback for project-based assessment: a case study of the graphic design critique. Retrieved August 23, 2009 from the http://www.polyu.edu.hk/ assessment/conference/.../bookdetails.htm 